\title{
Correction to: Theoretical investigations on enhancement of photovoltaic efficiency of nanostructured CZTS/ZnS/ZnO based solar cell device
}

\author{
S. Vallisree ${ }^{1} \cdot$ Anima Ghosh $^{1} \cdot$ R. Thangavel ${ }^{1} \cdot$ T. R. Lenka ${ }^{2}$
}

Published online: 23 February 2018

(c) Springer Science+Business Media, LLC, part of Springer Nature 2018

\section{Correction to:}

\section{Journal of Materials Science: Materials in Electronics} https://doi.org/10.1007/s10854-018-8715-y

The original version of this article was published with the following errors. This has been corrected with this erratum.

1. The original article inadvertently submitted and published without the name of one of the co-author, Anima Ghosh who has contributed experimental absorption data in the author group.

2. Figure 3 was wrongly published with the inset figure. The inset figure of Fig. 3 has been removed.

The corrected version of Fig. 3 and the caption is given below.

3. In section " 2 Simulation methodology", text below the Table 1, in the second sentence, the word "chargeollection", should read as "charge collection".

4. Equation Number 7 has incorrectly been published as

$$
\frac{E_{r}}{E_{i}}=\frac{n_{2} \cos \theta_{i}-n_{1} \cos \theta_{t}}{n_{1} \cos \theta_{i}+n_{2} \cos \theta_{t}}
$$

whereas it should be

$$
\frac{E_{r}}{E_{i}}=\frac{n_{1} \cos \theta_{i}-n_{2} \cos \theta_{t}}{n_{1} \cos \theta_{i}+n_{2} \cos \theta_{t}}
$$

The original article can be found online at https://doi.org/10.1007/ s10854-018-8715-y.

R. Thangavel

rthangavel@iitism.ac.in

1 Department of Applied Physics, Indian Institute of Technology (ISM), Dhanbad, Jharkhand 826004, India

2 Department of Electronics and Communication Engineering, National Institute of Technology Silchar, Silchar, Assam 788010, India

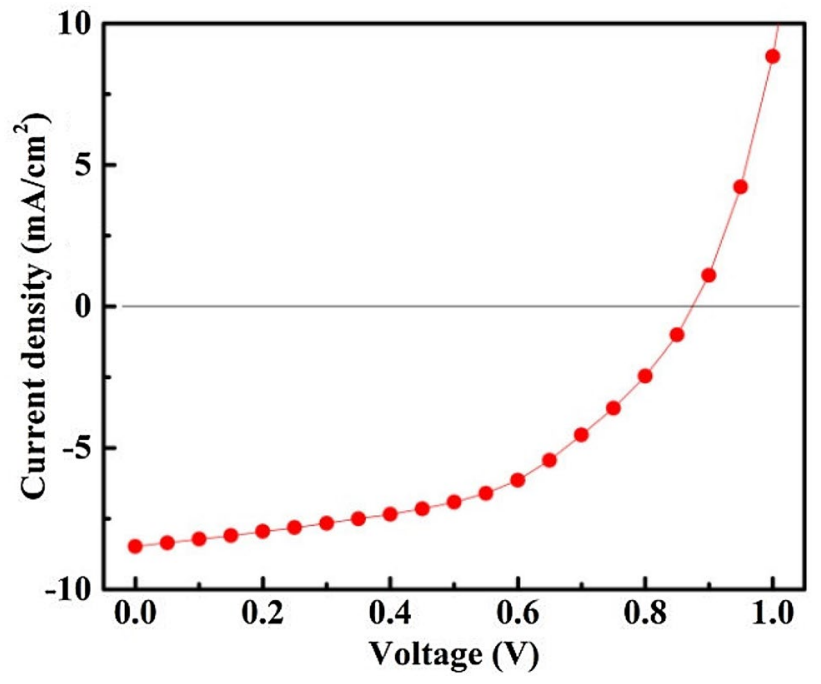

Fig. $3 \mathrm{~J}-\mathrm{V}$ characteristics of the CZTS solar cell device 